\title{
Ankle and Foot Pain and Associated Factors Among Nurses at Ayder Comprehensive Specialized Hospital, Mekelle, Ethiopia: Cross-Sectional Study
}

This article was published in the following Dove Press journal:

Journal of Pain Research

\section{Kefale Getie (iD) \\ Gebreslassie Kahsay (D) \\ Alemu Kassaw' \\ Gidey Gomera (iD) \\ Abayneh Alamer (D) \\ Tesfay Hailu ${ }^{2}$}

'Department of Physiotherapy, School of Medicine, College of Health Sciences, Mekelle University, Mekelle, Ethiopia;

${ }^{2}$ School of Public Health, College of Health Sciences, Mekelle University,

Mekelle, Ethiopia
Correspondence: Kefale Getie Mekelle University, PO Box 187I, Mekelle, Ethiopia

Tel +25l962543230

Email kefegete@gmail.com
Background: Ankle-foot pain is a significant public health problem in nurse professionals and has great burdens to the individuals, healthcare systems, and community at large. However, there is limited evidence on the prevalence of ankle-foot pain and its associated factors among nurses in Ethiopia. Thus, the finding of this study will help to address health problems resulting from ankle-foot pain among nurses.

Purpose: The aim of this study was to determine the prevalence and associated factors of ankles-foot pain among nurse working in Ayder Comprehensive Specialized Hospital, Tigray, Ethiopia.

Patients and Methods: An institutional-based cross-sectional study was conducted on a total of 366 nurses, and a simple random sampling technique was used to recruit study participants. Data were collected by using a self-administered adapted standardized Nordic questionnaire. Descriptive statistics and a bivariate logistic regression model were done to identify factors associated with ankle-foot pain. Those variables with a $P$-value less than 0.05 with $95 \% \mathrm{CI}$ in multivariate model were taken as statistically significant. Finally, AOR with $95 \%$ confidence interval at a $P$-value of $<0.05$ was reported.

Results: The prevalence of self-reported ankle-foot pain among nurses was $43.7 \%$ (95\% $\mathrm{CI}=38.5-49.1)$. Older age $(\mathrm{AOR}=7.669,95 \% \quad \mathrm{CI}=2.316-25.390)$, low shoe comfort $(\mathrm{AOR}=4.215, \quad 95 \% \quad \mathrm{CI}=2.031-8.745)$, multiple foot conditions $\quad(\mathrm{AOR}=6.102 \quad 95 \%$ $\mathrm{CI}=1.959-19.008)$, working night shifts $(\mathrm{AOR}=2.047,95 \% \mathrm{CI}=1.098-3.816)$, high physical demand $(\mathrm{AOR}=3.487,95 \% \mathrm{CI}=1.988-6.116)$, and nurses working in the intensive care unit $(\mathrm{AOR}=2.402,95 \% \mathrm{CI}=1.219-4.732)$ showed a statistically significant association with ankle-foot pain.

Conclusion: This study indicated that the prevalence of ankle-foot pain is commonly reported among nurses working in Ayder Comprehensive Specialized Hospital. Therefore, awareness and prevention of ankle and foot pain in nurses should be prioritized to reducing risk factors. Nurses should give attention to comfortable footwear, and further longitudinal research is recommended.

Keywords: prevalence, ankle and foot pain, nurses, associated factors, Ethiopia

\section{Introduction}

Ankle and foot pain is an abnormal sensory and emotional experience due to perceived inflammatory and degenerative damage to any tissue distal to the tibia or fibula that involves bones, joints, ligaments, muscles, tendons, retinacula, fascia, bursa, nerves, skin, nails, and vascular structures. ${ }^{1}$ Tissue injury in the ankle and 
foot could occur through mechanical, chemical, or thermal stimulation associated to trauma, musculoskeletal overload, infection, or systemic or proximal pathology. ${ }^{2}$ In developing countries nurses are pushed to work for long hours and deal with a large number of patients. ${ }^{3}$ Nursing is physically and psychologically demanding., ${ }^{4,5}$ Nurses are at high risk of ankle and foot pain due to high exposure to high physical demand and the fact that nurses stand and walk for long periods. ${ }^{6,7}$ Ankle-foot pain is largely common in workers who are engaged in prolonged walking and standing. ${ }^{8}$ The burden of ankle and foot pain reported in the general population reached up to $55.9 \%$. ${ }^{9}$ Ankle and foot pain is also common in white collar workers and the middle age population. ${ }^{10,11}$ According to a systematic review study, the reported prevalence of ankle-foot pain is varied between $11 \%$ and $55.3 \% .^{12}$ In the US, ankle-foot pain is a common problem among nursing professionals, $24 \%$ nurses were absent from work due to ankle-foot pain. ${ }^{13}$ In Australia, the prevalence of ankle-foot pain among nurses was reported as $55.3 \%$, and $20 \%$ of nurses described their problems had negative consequences on their activities at the workplace and home life. ${ }^{14}$ In studies from Japan, among nursing professionals, the reported prevalence was $23 \%$, and that prevented the nurses from performing activities of daily living and work was $4 \%$ and $17 \%$, respectively. ${ }^{15}$ Anklefoot pain can lead to significant health problems for nurses; however, it's burden and associated factors are not well known, particularly in Ethiopia. Thus, determining the magnitude of ankle-foot pain among nurses can be used to emphasize the preventive strategies of ankle and foot pain, thereby promoting health within the nursing personnel. Therefore, the purpose of this study was to assess the prevalence and associated factors of anklefoot pain among nurses working in Ayder Comprehensive Specialized Hospital, Ethiopia.

\section{Patients and Methods}

\section{Study Area and Period}

Mekelle, which is the capital city of Tigray National, Regional, State, is located around 783 kilometers North of Addis Ababa. The city has one specialized hospital (Ayder), three general hospitals, and several private clinics. Ayder Comprehensive Specialized Hospital (ACSH) has 2,185 staff, among these 750 are nurses. The study was conducted from April to May, 2019.

\section{Study Design and Population}

An institutional-based cross-sectional study was conducted. All nurses who were working at ACSH were included. Nurses who had less than 1 year of experience, foot deformities, known pregnant women, and recent surgeries and trauma of ankle-foot were excluded based on predetermined criteria.

\section{Sample Size Determination and Sampling Technique}

Sample size was calculated by single proportion formula, using the assumption of a $95 \%$ level of significance, the proportion of assumption or expected frequency $50 \%$ prevalence of ankle-foot pain, and a marginal error of 5\%, since no study has been done in the study area with the same populations. ${ }^{16}$ By considering 10\% non-response rate, the total sample was 274. Considering the second objective of this study the sample size was determined by a factor that nurses who were female were associated with ankle--foot pain with $95 \%$ confidence level, power of $80 \%$ ratio $=0.506, \mathrm{OR}=2,14$, percent of outcome in unexposed group $=48.3 \%$, and percent of outcome in exposed group $=64.2 \% .{ }^{17}$ Sample size, calculated by using the Epiinfo, was 366 and with a $10 \%$ non-response rate the final sample size was 403 . The study participants were selected using simple random sampling technique using lottery method.

\section{Data Collection Tool and Procedure}

Data was collected using the adapted standardized Nordic questionnaire through self-administration. ${ }^{18,19}$ This questionnaire includes; sociodemographic characteristics, psychosocial and behavioral factors, work related/mechanical (working hour per week, working night shift, working experience, static posture, awkward posture, lifting or lowering objects, and prolonged standing), and ankle/foot pain. The area of ankle/foot pain was assessed using transparent foot drawing. ${ }^{20}$ Subjects reporting foot and ankle pain were requested to mark the location of their ankle/foot pain on foot pictures. The level of shoe comforts of nurses was assessed by using a "Visual analog scale" for which 0 indicated "not comfortable" and 10 indicated the "highest level of comfortable". ${ }^{21}$ Psychosocial characteristics of the study participants were assessed by job content questionnaire using a 4-point Likert scale. ${ }^{2,23}$ 
To ensure the quality of the data, the data collectors and supervisors were trained in 1 day before the actual data collection how to approach the participants, and ethical issue. The supervisors were checked for the completeness and consistency of the data. Pre-test was done on $5 \%$ of the total sample in Mekelle general hospital before the actual data collection to check for the accuracy of the responses, language clarity, and appropriateness of the tools.

\section{Data Processing and Analysis}

The data were coded and entered using the Statistical Package for the Social Sciences (SPSS) Version 23 for analysis. Descriptive statistics were computed using frequencies with percentages for categorical variables, mean, and standard deviations for continuous variables. The relationship between ankle-foot pain and the associated factors was assessed using logistic regression analysis. To identify the potential associated factors, bivariate logistic regression analysis was done. Those variables with a $P$-value $<0.25$ in the bivariate logistic regression analysis were modeled into the multivariate logistic regression analysis. In multivariate logistic regression analysis, those variables with a $P$-value $<0.05$ were considered statistically significant. Model fitness was checked by Hosmer and Lemeshow goodness of fit test. Multicollinearity was checked by variance inflation factor (VIF) with the maximum value of 3.4.

\section{Operational Definitions}

Ankle-foot pain was defined as having trouble (perceived pain, ache, or any discomfort) in areas of ankle-foot region at least lasting 1 day in the last 12 months.

\section{Results \\ Socio-Demographic and Personal Characteristics}

A total of 366 nurses were enrolled in this study with a response rate of $90.8 \%$. Out of study participants, 259 $(70.8 \%)$ were female, and the mean age with standard deviation of the participants' was $31.21 \pm 5$. The majority of the participants $(282,77.0 \%)$ had a normal body mass index. The majority of them were married $(208,56.8 \%)$, and $363(99.2 \%)$ of the study participants were non- smokers. Of the total respondents, $72(19.9 \%)$ had reported low shoe comfort. Regarding self-reported foot conditions, 265 (72.4\%) nurses reported no foot condition (Table 1).

\section{Work-Related and Psychosocial Characteristics of Study Participants}

Out of the total respondents, 255 (42.3\%) study participants had less than 5 years working experiences. Regarding weekly working hour, 215 (58.7\%) study participants were working more than or equal to 48 hours per week. A total of $256(69.9 \%)$ participants was working night shifts. From the total study participants, $276(75.4 \%)$ were working in an awkward posture. Regarding psychosocial characteristics of the respondents, 199 (51.4\%) of them reported that their work needed high physical demand. A total of 216 (59\%) respondents reported a high psychological demand. From the total study participants, 352 (96.2\%) were having job stress (Table 2).

\section{Prevalence of Ankle-Foot Pain Among Study Participants}

The annual prevalence of ankle-foot pain was found to be $43.7 \%(95 \% \mathrm{CI}=38.5-49.1)$. Out of the study participants, $22(13.8 \%)$ reported pain location at the heel, $21(13.1 \%)$ pain at the big toes, $18(11.3 \%)$ ankle, 17 $(10.6 \%)$ plantar forefoot, $14(8.6 \%)$ medial arch, and 14 (8.8) were at lesser toes. The finding of this study reported that $43(23.5 \%)$ nurses were prevented from their daily activities due to the ankle-foot pain in last 12 months (Tables 2 and 3).

\section{Associated Factors with Ankle-Foot Pain Among Nurses}

In bivariate logistic regression analysis, self-reported anklefoot pain was significantly associated with; age, BMI, wear insole or sole, level of shoes comfort, foot condition, working area, working hours per week, working in night shift, awkward posture, static posture, lifting or lowering objects, prolonged standing, job stress, and physical demand. In multivariate logistic regression analysis, self-reported ankle-foot pain was significantly associated with older age pressure $(\mathrm{AOR}=7.669 ; 95 \% \mathrm{CI}=2.316-25.390)$, low shoes comfort at work $(\mathrm{AOR}=4.215 ; 95 \% \mathrm{CI}=2.031-8.745)$, two or more foot conditions ( $\mathrm{AOR}=6.102 ; 95 \% \mathrm{CI}=1.959-19.008)$, working in ICU/operation theater room ( $\mathrm{AOR}=2.402 ; 95 \%$ $\mathrm{CI}=1.219-4.732$ ), nurses working night shifts ( $\mathrm{AOR}=2.402$; 95\% $\mathrm{CI}=1.219-4.732$ ), and those who had high physical demand (3.487; 95\% CI=1.988-6.116) (Table 3). 
Table I Socio-Demographic Characteristics of Nurses Working in Mekelle University, ACSH, Tigray, Ethiopia, April 20I9 (n=366)

\begin{tabular}{|c|c|c|c|c|}
\hline \multirow[t]{2}{*}{ Variables } & \multirow{2}{*}{$\begin{array}{l}\text { Frequency } \\
\mathbf{N}\end{array}$} & \multirow{2}{*}{$\begin{array}{l}\text { Percentage } \\
\%\end{array}$} & \multicolumn{2}{|c|}{ Ankle-Foot Pain } \\
\hline & & & Yes (\%) & No (\%) \\
\hline \multicolumn{5}{|l|}{ Gender } \\
\hline Male & 107 & $29.2 \%$ & $43(40.2 \%)$ & 64 (59.8\%) \\
\hline Female & 259 & $70.8 \%$ & $117(45.2 \%)$ & 142 (54.8\%) \\
\hline \multicolumn{5}{|l|}{ Age (years) } \\
\hline $23-29$ & 173 & $47.3 \%$ & 70 (40.5\%) & 103 (59.5\%) \\
\hline $30-39$ & 161 & $44.0 \%$ & $66(41.0 \%)$ & 95 (59.0\%) \\
\hline$>39$ & 32 & $8.7 \%$ & $24(75.0 \%)$ & $8(25.0 \%)$ \\
\hline \multicolumn{5}{|l|}{ BMI } \\
\hline Underweight & 27 & $7.4 \%$ & $8(29.6 \%)$ & $19(70.4 \%)$ \\
\hline Normal weight & 282 & $77.0 \%$ & $122(43.3 \%)$ & $160(56.7 \%)$ \\
\hline Overweight & 57 & $15.6 \%$ & $30(52.6)$ & $27(47.4 \%)$ \\
\hline \multicolumn{5}{|l|}{ Marital status } \\
\hline Married & 208 & $56.8 \%$ & $94(45.2 \%)$ & $114(54.8 \%)$ \\
\hline Unmarried & 158 & $43.2 \%$ & $66(41.8 \%)$ & $92(58.2 \%)$ \\
\hline \multicolumn{5}{|l|}{ Had a child of $\leq 6$ years old } \\
\hline Yes & 140 & $61.7 \%$ & $64(45.7 \%)$ & $76(54.3 \%)$ \\
\hline No & 226 & $38.3 \%$ & $96(42.5 \%)$ & $130(57.5 \%)$ \\
\hline \multicolumn{5}{|l|}{ Smoking status } \\
\hline Yes & 3 & 0,8 & I (33.3\%) & $2(66.7)$ \\
\hline No & 363 & $99.2 \%$ & $159(43.8 \%)$ & $204(56.2 \%)$ \\
\hline \multicolumn{5}{|l|}{ Monthly income } \\
\hline $2,500-4,442$ & 108 & $29.5 \%$ & $43(39.8 \%)$ & $65(60.2 \%)$ \\
\hline $4,446-5,600$ & 138 & $37.7 \%$ & $58(42.0 \%)$ & $80(58.0 \%)$ \\
\hline $5,700-10,024$ & 120 & $32.8 \%$ & $59(49.2 \%)$ & $61(50.8 \%)$ \\
\hline \multicolumn{5}{|l|}{ Insole/sole user } \\
\hline Yes & 84 & $77.0 \%$ & $46(54.8 \%)$ & $38(45.2 \%)$ \\
\hline No & 282 & $23 \%$ & $114(40.4)$ & $168(59.6 \%)$ \\
\hline \multicolumn{5}{|l|}{ High heeled shoes } \\
\hline No & 294 & $80.4 \%$ & $130(44.2 \%)$ & $164(55.8 \%)$ \\
\hline Occasionally/I day a week & 47 & $12.8 \%$ & $20(42.6 \%)$ & $27(57.4 \%)$ \\
\hline Greater than or I day or more a week & 25 & $6.8 \%$ & $10(42.6 \%)$ & $15(57.4 \%)$ \\
\hline \multicolumn{5}{|l|}{ Level of shoe comfort } \\
\hline Low shoe comfort & 72 & $19.9 \%$ & $52(72.2 \%)$ & $20(27.8 \%)$ \\
\hline Medium shoe comfort & 114 & $30.9 \%$ & $57(50.0 \%)$ & $57(50.0 \%)$ \\
\hline High shoe comfort & 180 & $49.2 \%$ & $51(28.3 \%)$ & $129(71.7 \%)$ \\
\hline \multicolumn{5}{|l|}{ Foot condition } \\
\hline None & 265 & $72.4 \%$ & $98(37.0 \%)$ & $167(63.0 \%)$ \\
\hline One foot condition & 69 & $18.9 \%$ & $36(52.2 \%)$ & $33(47.8 \%)$ \\
\hline Two or more foot conditions & 32 & $8.7 \%$ & $26(81.2 \%)$ & $6(18.8)$ \\
\hline
\end{tabular}

\section{Discussion}

The purpose of this study was to determine the prevalence of ankle-foot pain and its associated factors. The prevalence of self-reported ankle-foot pain among nurses was $43.7 \%$ (95\% CI $=38.5-49.1)$. This finding indicated that ankle-foot pain is a high burden and health problem among nurses working at Ayder Comprehensive Specialized Hospital. The results of the present study showed that ankle-foot pain among nurses had a significant relationship with; age 40 years and older, 
Table 2 Work-Related and Psychosocial Characteristics of Nurses Working at MU, ACSH, Tigray, Ethiopia, April 2019 ( $\mathrm{n}=366$ )

\begin{tabular}{|c|c|c|c|c|c|}
\hline \multirow[t]{2}{*}{ Variables } & \multirow[t]{2}{*}{ Categories } & \multirow{2}{*}{$\begin{array}{l}\text { Frequency } \\
\mathrm{N}\end{array}$} & \multirow{2}{*}{$\begin{array}{l}\text { Percentage } \\
\%\end{array}$} & \multicolumn{2}{|c|}{ Ankle/Foot Pain } \\
\hline & & & & Yes & No \\
\hline \multirow[t]{3}{*}{ Working experience } & $<5$ years & 155 & $42.3 \%$ & $62(40.0 \%)$ & $93(60.0 \%)$ \\
\hline & $5-10$ years & 149 & $40.7 \%$ & $68(45.6 \%)$ & 81 (54.4\%) \\
\hline & $>10$ & 62 & $16.9 \%$ & $30(48.4 \%)$ & $32(51.6 \%)$ \\
\hline \multirow[t]{4}{*}{ Working area } & Ward & 155 & $42.3 \%$ & $59(38.1 \%)$ & $96(61.9 \%)$ \\
\hline & OPD & 74 & $20.2 \%$ & $30(40.5 \%)$ & 44 (59.5\%) \\
\hline & ICU/OR & 92 & $25.1 \%$ & $5 \mathrm{I}(55.4 \%)$ & $4 \mid(44.6 \%)$ \\
\hline & Emergency & 45 & $12.3 \%$ & $20(44.4 \%)$ & $25(55.6 \%)$ \\
\hline \multirow[t]{2}{*}{ Night shift } & Yes & 256 & $69.9 \%$ & $123(48.0 \%)$ & $133(52.0 \%)$ \\
\hline & No & 110 & $30.1 \%$ & $37(33.6 \%)$ & $73(66.4 \%)$ \\
\hline \multirow[t]{3}{*}{ Weekly working hours } & $<40$ hours & 112 & $30.6 \%$ & $40(35.7 \%)$ & 72 (64.3\%) \\
\hline & $40-47$ hours & 39 & $10.7 \%$ & 21 (53.8\%) & $18(46.2 \%)$ \\
\hline & $\geq 48$ hours & 215 & $58.7 \%$ & $99(46.0 \%)$ & 116 (54.0\%) \\
\hline \multirow[t]{2}{*}{ Static posture } & No & 87 & $23.8 \%$ & $19(21.8 \%)$ & $68(78.2 \%)$ \\
\hline & Yes & 279 & $76.2 \%$ & $14 \mid(50.5 \%)$ & $138(49.5 \%)$ \\
\hline \multirow[t]{2}{*}{ Awkward posture } & No & 90 & $24.6 \%$ & $25(27.8 \%)$ & 65 (72.2\%) \\
\hline & Yes & 276 & 75.4 & $135(48.9 \%)$ & $14 \mid(5|| \%)$. \\
\hline \multirow[t]{2}{*}{ Lifting or lowering objects } & No & 149 & $40.7 \%$ & 49 (32.9\%) & $100(67.1 \%)$ \\
\hline & Yes & 217 & $59.3 \%$ & $\mathrm{III}(5 \mathrm{I} .2 \%)$ & $106(48.8 \%)$ \\
\hline Prolonged standing & No & 71 & $19.4 \%$ & $14(19.7 \%)$ & 57 (80.3\%) \\
\hline \multirow[t]{3}{*}{ Physical demand } & Yes & 295 & $80.6 \%$ & $146(49.5 \%)$ & 149 (50.5\%) \\
\hline & Low physical demand & 166 & $45.4 \%$ & $39(23.5 \%)$ & $127(76.5 \%)$ \\
\hline & High physical demand & 199 & $54.4 \%$ & $121(60.8 \%)$ & 78 (39.2\%) \\
\hline \multirow[t]{2}{*}{ Job control } & Low job control & 188 & $51.4 \%$ & $80(42.6 \%)$ & $108(57.4 \%)$ \\
\hline & High job control & 178 & $48.6 \%$ & $80(44.9 \%)$ & $98(55.1 \%)$ \\
\hline \multirow[t]{2}{*}{ Psychological demand } & Low psychological demand & 150 & $41 \%$ & $62(41.3 \%)$ & $88(58.7 \%)$ \\
\hline & High psychological demand & 216 & $59 \%$ & $98(45.4 \%)$ & II 8 (54.6\%) \\
\hline \multirow[t]{2}{*}{ Low strain index } & Low strain index & 184 & $50.3 \%$ & $75(40.8 \%)$ & $109(59.2 \%)$ \\
\hline & High strain index & 182 & $49.7 \%$ & $85(46.7 \%)$ & $97(53.3 \%)$ \\
\hline \multirow[t]{2}{*}{ Job stress } & Yes & 352 & $96.2 \%$ & $156(44.3 \%)$ & 196 (55.7\%) \\
\hline & No & 14 & $3.8 \%$ & $4(28.6 \%)$ & $10(71.4 \%)$ \\
\hline
\end{tabular}

working in the ICU/OR, low shoe comfort, having $\geq 2$ foot conditions, high physical demand, and working night shifts.

The finding of this study was comparable with the studies done in Saudi Arabia (41.5\%), Pakistan (47.2\%), and Kenya (48.5\%). ${ }^{3,15,24}$ The possible explanation could be those studies used a similar outcome measure to assess pain, had similar operational definition comparable mean ages of study participants, and comparable sample size with studies. The prevalence of this study was lower compared with studies conducted in Australia (55.3\%), the US (74\%), and Brazil (55.2\%). ${ }^{13,14,25}$ This variation may be due to those studies reporting higher overweight of participants, higher working hours, improved diagnostic facilities, and age of participants in their studies. For instance, the studies done in Australia and Brazil used a relatively high mean age of study participants, $37.6 \pm 10$ and $41.3 \pm 9.4$ years old, respectively. In addition to this, in both studies reported higher prevalence of overweight and higher 
Table 3 Factor Associated with Ankle-Foot Pain Among Nurses Working in Mekelle University, ACSH, Tigray, Ethiopia, April, 2019 $(n=366)$

\begin{tabular}{|c|c|c|c|c|c|}
\hline \multirow[t]{2}{*}{ Variables } & \multicolumn{2}{|c|}{ Ankle/Foot Pain } & \multicolumn{3}{|l|}{ OR 95\% Cl } \\
\hline & Yes & No & COR $(95 \% \mathrm{Cl})$ & AOR $(95 \% \mathrm{Cl})$ & $P$-value \\
\hline \multicolumn{6}{|l|}{ Age (years) } \\
\hline $23-29$ & 70 & 103 & 1 & I & I \\
\hline $30-39$ & 66 & 95 & $1.022(0.660-1.582)$ & I.I52 (0.65I-2.038) & 0.626 \\
\hline$\geq 40$ & 24 & 8 & $4.414(1.876-10.388)$ & $7.669(2.316-25.390)$ & $0.001 * *$ \\
\hline \multicolumn{6}{|l|}{ BMI } \\
\hline Underweight & 8 & 19 & $0.552(0.234$ I. .304$)$ & $0.480(0.175-1.312)$ & 0.152 \\
\hline Normal weight & 122 & 160 & 1 & 1 & I \\
\hline Overweight & 30 & 27 & $\mathrm{I} .457$ (0.823 2.579) & $1.219(0.578-2.570)$ & $0.603 *$ \\
\hline \multicolumn{6}{|l|}{ Wear insole or orthosis } \\
\hline Yes & 46 & 38 & $1.784(1.092-2.915)$ & $\mathrm{I} .385(0.74 \mathrm{I}-2.589)$ & 0.308 \\
\hline No & 114 & 168 & I & I & \\
\hline \multicolumn{6}{|l|}{ Shoes comfort } \\
\hline Low shoes comfort & 52 & 20 & $6.576(3.576-12.093)$ & $4.215(2.03 \mathrm{I}-8.745)$ & $<0.00 I^{* *}$ \\
\hline Medium shoes comfort & 57 & 57 & $2.529(1.550-4.128)$ & $2.034(1.126-3.673)$ & $0.002 * *$ \\
\hline High shoes comfort & 51 & 129 & I & I & 1 \\
\hline \multicolumn{6}{|l|}{ Foot condition } \\
\hline None & 98 & 167 & 1 & 1 & I \\
\hline One foot condition & 36 & 33 & $1.859(1.092-3.218)$ & $1.940(0.986-3.817)$ & 0.055 \\
\hline$\geq 2$ foot conditions & 26 & 6 & $7.384(3.077-19.338)$ & $6.102(1.959-19.008)$ & $0.002 *$ \\
\hline \multicolumn{6}{|l|}{ Working hours per week } \\
\hline$<40$ hours & 40 & 72 & I & I & 1 \\
\hline 40-47 hours & 21 & 18 & $2.100(1.003-4.396)$ & $2.133(0.850-5.354)$ & $0.107^{*}$ \\
\hline$\geq 48$ hours & 99 & 116 & $1.536(0.960-2.459)$ & $1.135(0.611-2.106)$ & 0.689 \\
\hline \multicolumn{6}{|l|}{ Working area } \\
\hline Ward & 37 & 96 & 1 & I & I \\
\hline OPD & 35 & 44 & $1.109(0.630-1.954)$ & $1.448(0.738-2.839)$ & 0.281 \\
\hline ICU/OR & 26 & 41 & $2.024(1.199-3.417)$ & $2.402(1.219-4.732)$ & 0.011 \\
\hline Emergency & 62 & 25 & $1.302(0.665-2.548)$ & $1.748(0.740-4.128)$ & 0.203 \\
\hline \multicolumn{6}{|l|}{ Working in night shift } \\
\hline Yes & 123 & 133 & $1.825(1.146-2.906)$ & $2.047(1.098-3.816)$ & $0.024 * *$ \\
\hline No & 37 & 73 & I & I & I \\
\hline \multicolumn{6}{|l|}{ Prolonged standing } \\
\hline Yes & 146 & 149 & $3.989(2.130-7.473)$ & $1.025(0.486-2.161)$ & 0.234 \\
\hline No & 14 & 57 & I & I & 1 \\
\hline \multicolumn{6}{|l|}{ Static posture } \\
\hline Yes & $|4|$ & 138 & $3.657(2.0886 .403)$ & $1.734(0.813-3.699)$ & 0.154 \\
\hline No & 19 & 68 & I & I & I \\
\hline \multicolumn{6}{|l|}{ Awkward posture } \\
\hline Yes & 135 & $|4|$ & $2.489(1.483-4.179)$ & $1.025(0.486-2.161)$ & 0.949 \\
\hline No & 25 & 65 & I & I & I \\
\hline \multicolumn{6}{|l|}{ Lifting or lowering objects } \\
\hline Yes & $\mathrm{III}$ & 106 & $2.137(1.386-3.296)$ & $1.405(0.790-2.498)$ & 0.247 \\
\hline No & 49 & 100 & I & I & I \\
\hline
\end{tabular}

(Continued) 
Table 3 (Continued).

\begin{tabular}{|l|l|l|l|l|l|}
\hline \multirow{2}{*}{ Variables } & \multicolumn{2}{|l|}{ Ankle/Foot Pain } & \multicolumn{2}{l|}{ OR 95\% Cl } & AOR (95\% Cl) \\
\cline { 2 - 6 } & Yes & No & COR (95\% CI) & & P-value \\
\hline $\begin{array}{l}\text { Physical demand } \\
\text { Low physical demand }\end{array}$ & 39 & 127 & 1 & 1 & 1 \\
High physical demand & 121 & 78 & $5.052(3.195-7.986)$ & $3.487(1.988-6.116)$ & $<0.001 * *$ \\
\hline
\end{tabular}

Notes: I=Reference, *Significant in binary logistic regression. **Significant in multivariate logistic regression.

Abbreviations: $\mathrm{COR}$, crude odd ratio; $\mathrm{AOR}$, adjusted odds ratio; $\mathrm{Cl}$, confidence interval.

working hours per week than the current study. Another reason may be due to the difference in scope of practice, socio-cultural environments, and healthcare systems.

However, the prevalence of this study is higher than the studies conducted in Japan and Uganda, which indicated that annual prevalence of ankle-foot pain among nurses was $23 \%$ and $38.1 \%$, respectively. ${ }^{15,26}$ This may be due to the younger age of study participants, lower weekly working hours, different operational definition, lower overweight of participants reported, and differences in work setup. For instance, in a study done in Japan participants were younger ( $<30$ years were $58 \%$ ), with lower weekly working hours, and also lower reported overweight of study participants, which was $9 \%$, whereas this study reported overweight was $15.6 \% .^{15}$ Similarly, a study done in Uganda used purposive sample methods but this study used simple random methods. This study revealed that nurses aged 40 years and older were 7.66times more likely to develop ankle/foot pain. This study was supported by the study done in Japan which showed that nurses who were aged greater than 50 years old had a positive association with ankle-foot pain. ${ }^{15}$ Likewise, it is also supported by other studies conducted in the US and Sweden which indicated that there was a significant association between being aged 40 years and older and ankle/ foot pain. ${ }^{27,28}$ A systematic review done by Thomas et al ${ }^{10}$ in the general population showed that advanced age increases the risk of ankle-foot pain. The possible reason may be, in older age population the pathophysiological process alteration had occurred and different conditions are reported such as; osteoporosis, degeneration of ankle--foot joints, and this might lead them to develop ankle-foot pain. On the contrary, this study is not supported by two different studies done in Australia. This is may be due to nurses working in Australia having training about keeping them up-to-date with ankle and foot conditions. $^{8,14}$
This study revealed that nurses who had low shoe comfort were 4-times more likely to develop ankle/foot pain than those who had high shoes comfort $(\mathrm{AOR}=4.215 ; 95 \%$ $\mathrm{CI}=2.031-8.745, P<0.001)$. The current study was supported by a study done in Japan which showed that having low shoe comfort was 2-times more likely to develop ankle/foot pain. ${ }^{15}$ This might be due to both studies using similar assessment tools to assess the level of shoe comfort. The present study was also supported by a study done in Taiwan indicated that providing comfortable footwear for clinical nurses is essential for decreased fatigue and discomfort in the lower extremity. However, Chiu and Wang's ${ }^{29}$ study did not indicate the shoe comfort or its association with foot and ankle pain. Despite this fact, a qualitative study done in Turkey indicated that poor-fitting footwear leads to shoe discomfort and causes ankle-foot pain, tiredness, numbness, and digital deformities. ${ }^{30}$ This might be as low shoes comfort means that feet are exposed to low shock absorption, high friction force, and high foot impact force causing strain, plantar fasciitis, and abnormal arch, which lead to anklefoot pain. ${ }^{31,32}$

This study revealed that nurses who had reported two or more foot conditions were 6-times more likely to develop ankle/foot pain than those who had no foot condition. The findings of this study were consistent with a study done in Australia which showed that nurses having two or more foot conditions were 5.59-times more likely to develop ankle/foot pain than those who had no foot condition. $^{14}$ This could be as foot conditions like flat foot, bunions, toe deformities, high arches, callous/corn, and heel spur have been associated with ankle/foot pain and this foot condition is a contributing factor for poor foot posture, gait instability, uneven weight distribution, and poor balance, which leads to ankle-foot pain. ${ }^{33}$

This study showed that nurses who had high physical demand were 3.48-times more likely to develop ankle/ foot pain than those who had low physical demand. This 
study finding agreed with two different studies done in Iran. ${ }^{17,34}$ This could be as both studies use a simple random sampling method and the same study design. Similarly, a study conducted in Japan indicated that nurses having high physical exertion were statistically correlated with ankle-foot pain. The possible explanation might be that nurses who have high physical demand will have high mechanical stress on the anklefoot region and this could cause strain in the ankle and foot area, which leads to the development of ankle-foot pain. ${ }^{30}$ Nurses who were working in the ICU/OR were reported to be 2-times more likely to develop ankle-foot pain compared to those working in ward, Emergency unit, and OPD. This study agreed with a study done in Australia. ${ }^{14}$ This could be that nurses working in the $\mathrm{OR} / \mathrm{ICU}$ are exposed to working in a prolonged fixed standing position for long durations, which might cause them to be unpleasant, with swelling, numbness, and more mechanical stress than others. ${ }^{35}$ This could lead to the development of ankle-foot pain. In this study, other work-related factors revealed that nurses who were working a night shift were 2-times more likely to develop ankle/foot pain than those who were not working a night shift $(\mathrm{AOR}=2.047 ; 95 \% \mathrm{CI}=1.098-3.816$, $P=0.024)$. This study finding is in line with a study conducted in Korea which indicated that nurses working a night shift were associated with ankle-foot pain. ${ }^{36}$ This may be due to the fact that nurses working the night shift may not get enough rest time and have a high work load, which might lead them to develop ankle-foot pain. On the contrary, a study conducted in Japan indicated nurses working the night shift were not associated with ankle-foot pain. ${ }^{15}$ This could be nurses working in Japan may takes enough snaps, and have a low work load and good working conditions.

\section{Conclusion}

The findings of this study show that ankle-foot pain is a common health problem among nurses in Ethiopia. The results of the present study show that ankle-foot pain among nurses has a significant correlation with being old age, poor shoe comfort, having multiple underlying foot conditions, high physical demand, and work-related factors like nurses working in the ICU/OR, found to be independently associated with ankle-foot pain. This may lead to a negative impact on nursing care practice and their work performance. Nurses are recommended to give attention to comfortable footwear, keep their ankle/foot health, and further longitudinal researches with objective measurements is recommended.

\section{Abbreviations}

AOR, adjusted odds ratio; ACSH, Ayder Comprehensive Specialized Hospital; BMI, body mass index; COR, crude odds ratio; CI, confidence interval; OR, odds ratio; SNQ, Standard Nordic Questionnaire; SPSS, Statistical Package for Social Sciences; VAS, Visual Analog Scale; WHO, World Health Organization; ICU, intensive care unit; OR, operation theater.

\section{Data Sharing Statement}

Since this is a funded work, the raw data is the property of Mekelle University. Data sharing can be arranged by the data collectors for a reasonable formal request.

\section{Ethics Approval and Consent to Participate}

Ethical clearance was obtained from the Health Research Ethics Review Committee Mekelle University, College of Health Sciences in accordance with Helenski declaration. Written informed consent was obtained from each of the study participants after being informed in detail about the objective, purpose, benefit, risk, and the confidentiality of information and the voluntary nature of participation.

\section{Acknowledgments}

We are grateful to college and health sciences, Mekelle University for funding the project. We would like to express our special thanks to all study participants for giving their time during data collection, and to Ayder Comprehensive Specialized Hospital, medical director for providing us all the necessary information.

\section{Funding}

This work was fully funded by Mekelle University. The funder has no role in the design of the study, data collection, and analysis, interpretation of data and in writing the manuscript.

\section{Disclosure}

The authors declare that they have no conflicts of interest for this work. 


\section{References}

1. Hawke F, Burns J. Understanding the nature and mechanism of foot pain. J Foot Ankle Res. 2009;2(1):1. doi:10.1186/1757-1146-2-1

2. Maganaris CN, Narici MV, Almekinders LC, Maffulli N. Biomechanics and pathophysiology of overuse tendon injuries. Sports Med. 2004;34(14):1005-1017. doi:10.2165/00007256200434140-00005

3. Tanui BC Assessment of Work-Related Musculoskeletal Disorders among Nurses in Mombasa County, Kenya: COHES, JKUAT. 2016.

4. Myny D, Van Hecke A, De Bacquer D, et al. Determining a set of measurable and relevant factors affecting nursing workload in the acute care hospital setting: a cross-sectional study. Int J Nurs Stud. 2012;49(4):427-436. doi:10.1016/j.ijnurstu.2011.10.005

5. Smith DR, Sato M, Miyajima T, Mizutani T, Yamagata Z. Musculoskeletal disorders self-reported by female nursing students in central Japan: a complete cross-sectional survey. Int J Nurs Stud. 2003;40(7):725-729. doi:10.1016/S0020-7489(03)00012-9

6. De Souza C, Lima da Silva J, Antunes Cortez E, Schumacher K, Moreira R, De Almeida Nilson T. Riscos ergonômicos ósteomioesqueléticos na equipe de enfermagem em âmbito hospitalar. Enfermería Global. 2001;23:264-276.

7. Rauber Gallas S, Fontana RT. Biossegurança e a enfermagem nos cuidados clínicos: contribuições para a saúde do trabalhador. Rev Bras Enferm. 2010;63(5).

8. Reed LF. An Investigation of Foot and Ankle Problems Experienced by Nurses. Queensland University of Technology; 2007.

9. Mølgaard C, Lundbye-Christensen S, Simonsen O. High prevalence of foot problems in the Danish population: a survey of causes and associations. Foot. 2010;20(1):7-11. doi:10.1016/j.foot.2010.03.002

10. Thomas MJ, Roddy E, Zhang W, Menz HB, Hannan MT, Peat GM. The population prevalence of foot and ankle pain in middle and old age: a systematic review. Pain. 2011;152(12):2870-2880. doi:10.1016/j.pain.2011.09.019

11. Chua YP, Tan WJ, Yahya T, Saw A. Prevalence of nontraumatic foot pain among urban young working women and its contributing factors. Singapore Med J. 2013;54(11):630-633. doi:10.11622/smedj.2013223

12. Stolt M, Suhonen R, Virolainen P, Leino-Kilpi H. Lower extremity musculoskeletal disorders in nurses: a narrative literature review. Scand J Public Health. 2016;44(1):106-115. doi:10.1177/ 1403494815602989

13. Sheikhzadeh A, Gore C, Zuckerman JD, Nordin M. Perioperating nurses and technicians' perceptions of ergonomic risk factors in the surgical environment. Appl Ergon. 2009;40(5):833-839. doi:10.1016 j.apergo.2008.09.012

14. Reed LF, Battistutta D, Young J, Newman B. Prevalence and risk factors for foot and ankle musculoskeletal disorders experienced by nurses. BMC Musculoskelet Disord. 2014;15(1):196. doi:10.1186/ 1471-2474-15-196

15. Tojo M, Yamaguchi S, Amano N, et al. Prevalence and associated factors of foot and ankle pain among nurses at a university hospital in Japan: a cross-sectional study. J Occup Health. 2018;60:132-139. doi:10.1539/joh.17-0174-OA

16. Degu G, Tessema F. Biostatistics for Health Science Students: Lecture Note Series. Addis Ababa: The Carter Center (9EPHTI); 2005.

17. Choobineh A, Movahed M, Tabatabaie SH, Kumashiro M. Perceived demands and musculoskeletal disorders in operating room nurses of Shiraz city hospitals. Ind Health. 2010;48(1):74-84. doi:10.2486/ indhealth. 48.74

18. Smith DR, Mihashi M, Adachi Y, Koga H, Ishitake T. A detailed analysis of musculoskeletal disorder risk factors among Japanese nurses. J Safety Res. 2006;37(2):195-200. doi:10.1016/j.jsr.200 6.01 .004
19. Kuorinka I, Jonsson B, Kilbom A, et al. Standardised Nordic questionnaires for the analysis of musculoskeletal symptoms. Appl Ergon. 1987;18(3):233-237. doi:10.1016/0003-6870(87)90010-X

20. Chatterton BD, Muller S, Thomas MJ, Menz HB, Rome K, Roddy E. Inter and intra-rater repeatability of the scoring of foot pain drawings. J Foot Ankle Res. 2013;6(1):44. doi:10.1186/1757-1146-6-44

21. Mills K, Blanch P, Vicenzino B. Identifying clinically meaningful tools for measuring comfort perception of footwear. Med Sci Sports Exerc. 2010;42(10):1966-1971. doi:10.1249/MSS.0b013e3181 dbacc8

22. Karasek R, Brisson C, Kawakami N, Houtman I, Bongers P, Amick B. The Job Content Questionnaire (JCQ): an instrument for internationally comparative assessments of psychosocial job characteristics. J Occup Health Psychol. 1998;3(4):322. doi:10.1037/1076-8998.3.4.322

23. Kawakami N, Fujigaki Y. Reliability and validity of the Japanese version of Job Content Questionnaire: replication and extension in computer company employees. Ind Health. 1996;34(4):295-306. doi:10.2486/indhealth.34.295

24. Tariq S. Prevalence of foot and ankle musculoskeletal disorders in nurses of Lahore Pakistan. Global J Med Res. 2018.

25. Santos E, Andrade RD, Lopes SGR, Valgas C. Prevalence of musculoskeletal pain in nursing professionals working in orthopedic setting. Revista Dor. 2017;18(4):298-306. doi:10.5935/1806-0013.20170119

26. Munabi IG, Buwembo W, Kitara DL, Ochieng J, Mwaka ES. Musculoskeletal disorder risk factors among nursing professionals in low resource settings: a cross-sectional study in Uganda. $B M C$ Nurs. 2014;13(1):7. doi:10.1186/1472-6955-13-7

27. Nealy R, McCaskill C, Conaway MR, Burns SM. The aching feet of nurses: an exploratory study. Med Surg Nurs. 2012;21(6):354-359.

28. Arvidsson I, Simonsen JG, Dahlqvist C, et al. Cross-sectional associations between occupational factors and musculoskeletal pain in women teachers, nurses and sonographers. BMC Musculoskelet Disord. 2016;17(1):35. doi:10.1186/s12891-016-0883-4

29. Chiu M-C, Wang MJJ. Professional footwear evaluation for clinical nurses. Appl Ergon. 2007;38(2):133-141. doi:10.1016/j.apergo.200 6.03.012

30. Stolt M, Miikkola M, Suhonen R, Leino-Kilpi H. Nurses' perceptions of their foot health: implications for occupational health care. Workplace Health Saf. 2018;66(3):136-143. doi:10.1177/ 2165079917727011

31. Hillstrom H, Whitney K, McGuire J, et al. Biomechanical assay of a specially designed insole for plantar fasciitis/heel spur syndrome. Gait Posture. 1996;4(2):195. doi:10.1016/0966-6362(96)80633-3

32. Kogler G, Solomonidis S, Paul J. Biomechanics of longitudinal arch support mechanisms in foot orthoses and their effect on plantar aponeurosis strain. Clin Biomech. 1996;11(5):243-252. doi:10.1016/ 0268-0033(96)00019-8

33. Garrow AP, Silman AJ, Macfarlane GJ. The Cheshire Foot Pain and Disability Survey: a population survey assessing prevalence and associations. Pain. 2004;110(1):378-384. doi:10.1016/j. pain.2004.04.019

34. Choobineh A, Rajaeefard A, Neghab M. Association between perceived demands and musculoskeletal disorders among hospital nurses of Shiraz University of Medical Sciences: a questionnaire survey. Int J Occup Saf Ergon. 2006;12(4):409-416. doi:10.1080/ 10803548.2006.11076699

35. Park HH, Yi G. A study on the subjective musculoskeletal symptoms associated with tasks of operating room nurses. $J$ Korean Acad Commun Health Nurs. 2005;16(3):351-359.

36. Ryu E, Ye B, Yi Y, Kim J. Risk factors of musculoskeletal symptoms in university hospital nurses. Ann Occup Environ Med. 2014;26 (1):47. doi:10.1186/s40557-014-0047-7 


\section{Publish your work in this journal}

The Journal of Pain Research is an international, peer reviewed, open access, online journal that welcomes laboratory and clinical findings in the fields of pain research and the prevention and management of pain. Original research, reviews, symposium reports, hypothesis formation and commentaries are all considered for publication. The manuscript management system is completely online and includes a very quick and fair peer-review system, which is all easy to use. Visit http:// www.dovepress.com/testimonials.php to read real quotes from published authors.

Submit your manuscript here: https://www.dovepress.com/journal-of-pain-research-journal 